\title{
РАЗДЕЛЕНИЕ ИЗОТОПОВ НИКЕЛЯ В ПРОЦЕССЕ ЗАПОЛНЕНИЯ КАСКАДА ГАЗОВЫХ ЦЕНТРИФУГ С РАЗЛИЧНЫМ КОЛИЧЕСТВОМ СТУПЕНЕЙ
}

\author{
Ушаков А. А. ${ }^{1,}$, Орлов А. А. ${ }^{1}$, Совач В. П. ${ }^{2}$ \\ ${ }^{1}$ Томский политехнический университет, 634050, г. Томск, пр-m Ленина, 30 \\ ${ }^{2} \mathrm{AО}$ «ПО ЭХЗ», 663690, Красноярский край, г. Зеленогорск, \\ ул. Первая Промышленная, 1 \\ e-mail: ushakovaa2015@sibmail.com
}

При эксплуатации каскада газовых центрифуг (ГЦ) для разделения многокомпонентных изотопных смесей (МИС) возникают нестационарные гидравлические и разделительные процессы. Режиму разделения МИС в каскаде ГЦ предшествует нестационарный процесс его заполнения рабочим веществом. До настоящего времени моделирование и изучение этого процесса ни кем не проводилось. Ранее нами была разработана математическая модель нестационарных гидравлических и разделительных процессов [1, 2] и проведена ее верификация на примере разделения изотопов германия, криптона, кремния и вольфрама.

В данной работе приведены результаты исследований процесса заполнения каскада с различным количеством ступеней для случая разделения изотопов никеля, которые используются в ядерно-физических исследованиях и для получения радиоактивных изотопов (например, изотоп ${ }^{62} \mathrm{Ni}$ используется для получения радиоактивного изотопа ${ }^{63} \mathrm{Ni}$ ).

Изотопы никеля распределяются по каскаду в соответствии с их массовыми числами независимо от количества ступеней каскада. Увеличение числа ступеней в каскаде приводит к повышению максимальных значений концентраций изотопов. Установлено, что концентрации изотопов никеля в потоках лёгкой и тяжёлой фрракции после заполнения каскада зависят от количества ступеней в каскаде.

\section{ЛИТЕРАТУРА}

1. Orlov A.A., Ushakov A.A., Sovach V.P. Mathematical model of nonstationary hydraulic processes in gas centrifuge cascade for separation of multicomponent isotope mixtures. MATEC Web of Conferences. - 2017. — Vol. 92. 01033.

2. Orlov A.A., Ushakov A.A., Sovach V.P. Mathematical model of nonstationary separation processes proceeding in the cascade of gas centrifuges in the process of separation of multicomponent isotope mixtures. Journal of Engineering Physics and Thermophysics. 2017. Vol. 90, № 2. P. 258-265. 